\title{
First report of Rhodnius montenegrensis (Hemiptera, Reduviidae, Triatominae) in the State of Acre, Brazil
}

\author{
Dionatas Ulises de Oliveira Meneguetti ${ }^{[1],[2]}$, Simone Delgado Tojal[2], \\ Pedro Raimundo Mathias de Miranda ${ }^{[2]}$, João Aristeu da Rosa ${ }^{[3]}$ \\ and Luis Marcelo Aranha Camargo ${ }^{[4],[5]}$
}

[1]. Programa de Pós Graduação em Biologia Experimental, Fundação Universidade Federal de Rondônia, Porto Velho, Rondônia, Brasil. [2]. Colégio de Aplicação, Universidade Federal do Acre, Rio Branco, Acre, Brasil. [3]. Departamento de Ciências Biológicas, Faculdade de Ciências Farmacêuticas, Universidade Estadual Paulista, Araraquara, São Paulo, Brasil. [4]. Instituto de Ciências Biomédicas, Universidade de São Paulo, Monte Negro, Rondônia, Brasil. [5]. Departamento de Medicina, Faculdade São Lucas, Porto Velho, Rondônia, Brasil.

\begin{abstract}
Introduction: This paper reports, for the first time, the presence of Rhodnius montenegrensis in the State of Acre, Brazil. Methods: Two female R. montenegrensis were collected in a dwelling in the rural area of Rio Branco, Acre, Brazil. Results: The occurrence of this species was confirmed, and the number of Triatominae species in the State of Acre increased from four to five. Conclusions: Further studies should be performed to reach a clearer understanding of the ecology of this arthropod, its possible role in transmitting Chagas' disease and rangeliosis, and its current geographical distribution in the region.
\end{abstract}

Keywords: Triatominae. Rhodnius montenegrensis. Western Amazon.

Triatomines, also known as conenose bugs, kissing bugs, or assassin bugs, are insects found throughout the Americas, distributed from the Southern part of the United States of America to Southern Argentina ${ }^{(1)}$. These insects are of great importance to public health as they are involved in transmission of South American trypanosomiasis, also called Chagas' disease $^{(2)}$ in honor of Carlos Chagas who first described this disease in $1909^{(1)(3)(4)}$.

In Brazil, there are eight genera of Triatominae: Alberprosenia, Belminus, Cavernicola, Eratyrus, Microtriatoma, Panstrongylus, Parabelminus, Psammolestes, Rhodnius, and Triatoma ${ }^{(5)(6)}$. In the State of Acre, researchers have reported the occurrence of four species of triatomines, namely, Rhodnius robustus ${ }^{(7)}$, Rhodnius pictipes, Panstrongylus geniculatus ${ }^{(8)}$, and Eratyrus mucronatus ${ }^{(9)}$. However, some R. robustus specimens collected in Acre may have been erroneously described by some researchers ${ }^{(7)}$ because of similarities with Rhodnius montenegrensis, which had not previously been shown to exist in this region.

Rhodnius montenegrensis was first described in 2012 from specimens collected in the municipality of Monte Negro, Rondônia, Brazil. These insects were initially identified as

Corresponding author: Dr. Dionatas Ulises de Oliveira Meneguetti. Rua Getúlio Vargas 654, Centro, 69900-060 Rio Branco, Acre, Brasil.

Phone 5568 9213-9022.

e-mail: dionatasmeneguetti@hotmail.com

Received 26 January 2015

Accepted 13 April 2015
Rhodnius robustus; however, subsequent studies showed that R. montenegrensis was a new species distinct from $R$. robustus ${ }^{(10)(11)}$.

In this study, we report, for the first time, the presence of $R$. montenegrensis in the State of Acre, Brazil.

Two female of $R$. montenegrensis were collected in a dwelling in the rural area of Rio Branco, Acre, Brazil $\left(09^{\circ} 54^{\prime} 12.24^{\prime \prime} \mathrm{S}, 67^{\circ} 50^{\prime} 11.00^{\prime \prime} \mathrm{W}\right)$ on September 2014, with no characteristics of domiciliation on the site (Figure 1). The specimens were found in a dormitory built in masonry lined with wood without the occurrence of cracks, $200 \mathrm{~m}$ from a forest fragment. Several palm trees of the Attalea genera were located close to the dwelling; these trees may have acted as natural ecotopes for the species. It is believed that the insects may have been attracted by the light from the residence. The species $R$. montenegrensis has been described as occurring in palms of genus Attalea ${ }^{(10)}$ and Orbignya ${ }^{(11)}$, similar to other species of the genus Rhodnius ${ }^{(2)}$ (12), demonstrating the ecological importance of palm trees for these triatomines.

The specimens were collected with permission from the Brazilian Institute of Environment and Renewable Natural Resources [Instituto Brasileiro do Meio Ambiente e dos Recursos Naturais Renováveis (IBAMA); permanent license No. 10080-2].

The identification of triatomines was conducted in the Laboratory of Biological Sciences of the Federal University of Acre (UFAC), Rio Branco, Acre, Brazil, based on criteria previously described by Rosa et al ${ }^{(11)}$. Feces from the specimens were diluted in saline solution, prepared on microscope 


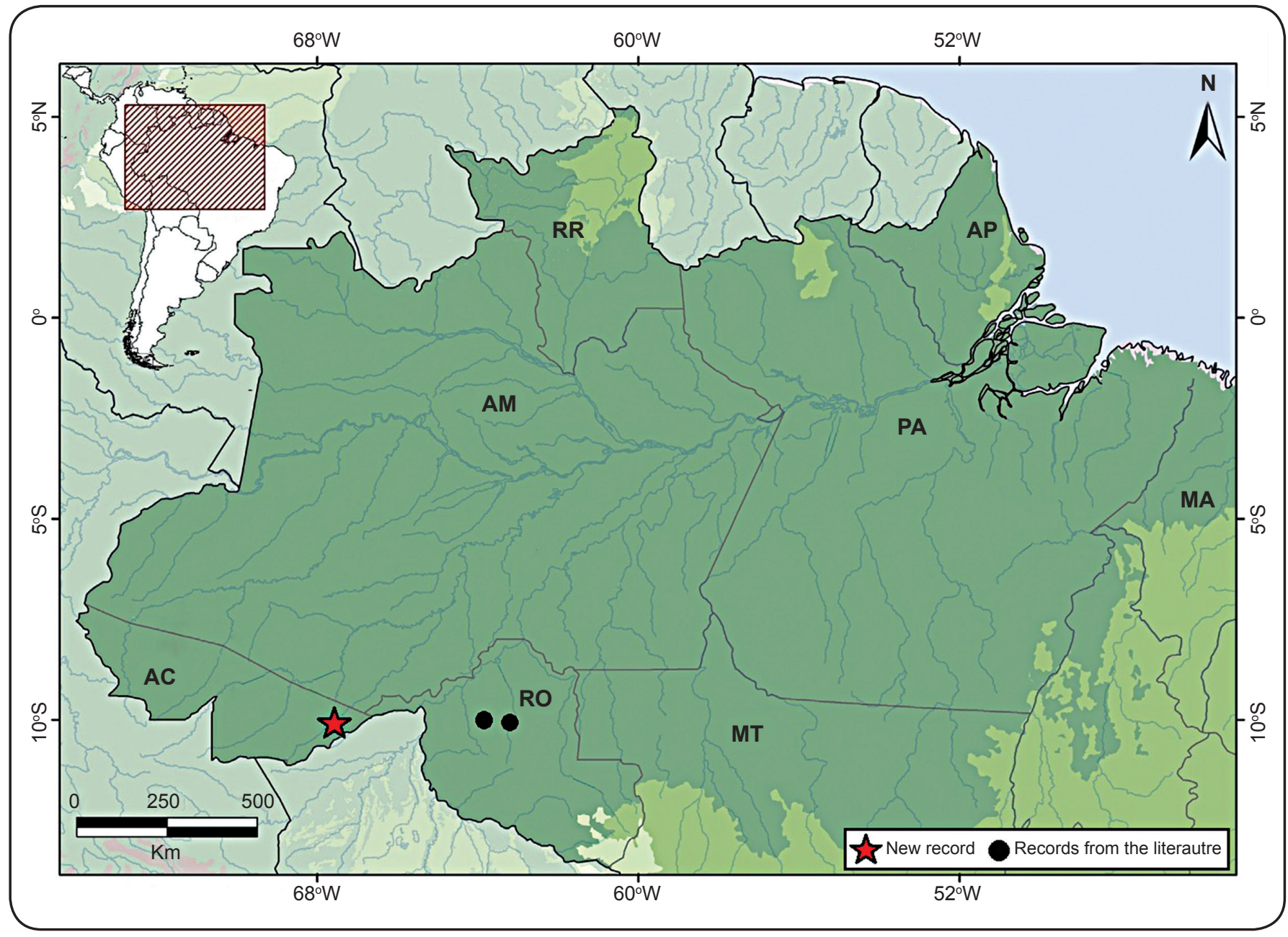

FIGURE 1 - Distribution of Rhodnius montenegrensis in Brazilian Amazonia. The black circles indicate the previously known distributions of Rhodnius montenegrensis in Rondônia ${ }^{(10),(11)}$, and the red star indicates the new record of Rhodnius montenegrensis in Rio Branco, State of Acre, Brazil. RR: Roraima; AP: Amapá; AM: Amazonas; PA: Pará; MA: Maranhão; AC: Acre; RO: Rondônia; MT: Mato Grosso.

slides, and then examined with an optical microscope $(640 \times$ magnification).

Rhodnius montenegrensis (Figure 2) showed some morphological differences from $R$. robustus, as follows. First, the head length of $R$. montenegrensis was significantly larger. Additionally, the anterior wings exhibited welldemarcated veins, notably the Sc veins, with a yellow tonality. $R$. montenegrensis also exhibited yellow legs, and the overall color of the insect was yellow, with the exception of a black stripe on the posterior tibial portion at the tarsus limit. The mesosternum exhibited two lateral stripes and one central stripe, delimiting two dark areas. The metasternum featured two yellow stripes between the medial coxa, delimiting a dark area in the center. On the abdomen, yellow spots interposed with dark spots were observed lengthwise over the ventral abdomen. Respiratory spiracles at the ventral abdomen are yellow for $R$. robustus, differing from those of $R$. montenegrensis, which are darker ${ }^{(11)}$.
The two specimens collected in this study were naturally infected with trypanosomatids. Thus, further studies are needed to confirm the species in order to better understand the ecological context and host-parasite relationships of triatomines in this region.

The presence of this additional triatomine species in the State of Acre increases the number of species from four to five, demonstrating that the biodiversity of these vectors may have been underestimated. Surrounding areas, such as Bolivia and the Brazilians States of Amazonas and Rondônia, have 16, 10, and 6 different species, respectively ${ }^{(5)}(8)(11)(12)(13)$. Therefore, further studies are needed to determine the triatomine fauna and their distributions throughout the state, particularly for species of the genus Rhodnius, which facilitate autochthonous transmission of American trypanosomiasis ${ }^{(8)}$ and are vectors of Trypanosoma rangeli, which is responsible for the occurrence of more than 2,700 human cases of rangeliosis ${ }^{(10)}$, with cases in the States of Amazonas and Bahia, Brazil ${ }^{(14)(15)}$. 


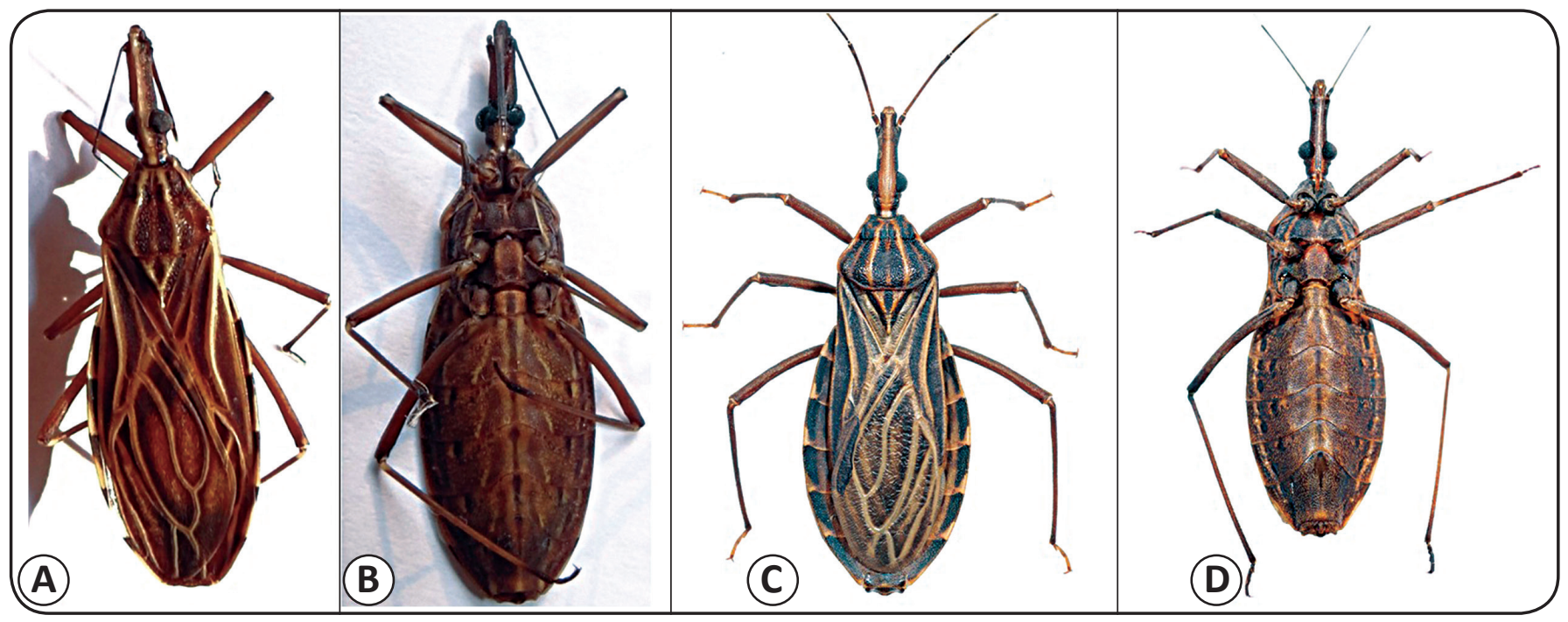

FIGURE 2 - A) Dorsal and B) Ventral views of Rhodnius montenegrensis individuals found in the municipality of Rio Branco, State of Acre, Brazil. C) Dorsal and D) Ventral views of Rhodnius robustus ${ }^{(11)}$.

\section{CONFLICT OF INTEREST}

The authors declare that there is no conflict of interest.

\section{REFERENCES}

1. Moncayo A, Silveira AC. Current epidemiological trends for Chagas disease in Latin America and future challenges in epidemiology, surveillance and health policy. Mem Inst Oswaldo Cruz 2009; 104:17-30.

2. Meneguetti DUO, Trevisan O, Camargo LMA, Rosa RM. Natural infection of triatomines (Hemiptera: Reduviidae) by trypanosomatids in two different environments in the municipality of Ouro Preto do Oeste - Rondônia, Brazil. Rev Soc Bras Med Trop 2012; 45:395-398.

3. Chagas C. Nova trypanosomíase humana. Estudo sobre a morfologia e o ciclo evolutivo do Schizotripanum cruzi n. gen. Sp, ajente etiolójico de nova entidade mórbida do homem. Mem Inst Oswaldo Cruz 1909; 1:159-218.

4. Coura JR. The discovery of Chagas disease (1908-1909): great successes and certain misunderstandings and challenges. Rev Soc Bras Med Trop 2013; 46:389-390.

5. Meneguetti DUO, Trevisan O, Rosa RM, Camargo LMA. First report of Eratyrus mucronatus, Stal, 1859 (Hemiptera, Reduviidae, Triatominae), in the State of Rondonia, Brazil. Rev Soc Bras Med Trop 2011; 44:511-512.

6. Galvão C, Carcavallo R, Rocha DS, Jurberg J. Checklist of the current valid species of the subfamily Triatominae Jeannet, 1919 (Hemiptera, Reduviidae) and their geographical distribution, with nomenclatural and taxonomic notes. Zootaxa 2003; 202:1-36.

7. Barata JMS, Rocha RM, Rodrigues VLCC, Ferraz-Filho AN. Primeiro caso autóctone de tripanossomíase americana no Estado do Acre (Brasil) e sua correlação com as cepas isoladas do caso humano e de triatomíneos silvestres da área. Rev Saude Publica 1988; 22:401-410.

8. Gurgel-Gonçalves RC, Galvão C, Costa J, Peterson AT. Geographic distribution of Chagas disease vectors in Brazil based on ecological niche modeling. J Trop Med 2012; 2012:1-15.

9. Obara MT, Cardoso AS, Pinto MCG, Souza CR, Silva RA, Gurgel-Gonçalves R. Eratyrus mucronatus Stål, 1859 (Hemiptera: Reduviidae: Triatominae): First report in the State of Acre, Brazil, and updated geographic distribution in South America. Check List 2013; 9:851-854,

10. Meneguetti DUO, Soares EB, Campaner M, Camargo LMA. First report of Rhodnius montenegrensis (Hemiptera: Reduviidae: Triatominae) infection by Trypanosoma rangeli. Rev Soc Bras Med Trop 2014; 47:374-376.

11. Rosa JA, Rocha CS, Sueli G, Mara CP, Vagner JM, Júlio CRFF, et al. Description of Rhodnius montenegrensis n. sp. (Hemiptera: Reduviidae: Triatominae) from the state of Rondônia, Brazil. Zootaxa 2012; 3478:62-76.

12. Massaro DC, Rezende DS, Camargo LMA. Estudo da fauna de triatomíneos e da Ocorrência de Doença de Chagas em Monte Negro, Rondônia, Brasil. Rev Bras Epidemiol 2008; 11:228-240.

13. Cortez MR. Triatominos de Bolivia y la enfermedad de Chagas. Ministerio de Salud y Deportes, Unidad de Epidemiología, Programa Nacional de Chagas; 2007.

14. Coura JR, Fernandes O, Arboleda M, Barrett TV, Carrada N, Degrave $\mathrm{W}$, et al. Human Infection by Trypanosoma rangeli in the Brazilian Amazon. Trans R Soc Trop Med Hyg 1996; 90: 278-279.

15. Sousa MA, Silva Fonseca T, Santos BN, Santos Pereira SM, Carvalhal C, Hasslocher Moreno AM. Trypanosoma rangeli Tejera, 1920, in chronic Chagas disease patients under ambulatory care at the Evandro Chagas Clinical Research Institute (IPECFIOCRUZ, Brazil). Parasitol Res 2008; 103:697-703. 